\title{
Desplazamiento intraurbano en Medellín por proyectos de desarrollo: retos de intervención para la Clínica Jurídica de Interés Público UNAULA
}

Luis Felipe Alzate Ramírez, Valentina Nohavá Rojas?

Recibido: junio 9 de 2019 - Aprobado: junio 29 de 2019

\begin{abstract}
Resumen
La creación de modelos de ciudad, a partir de intervenciones urbanísticas acordes con estándares del neoliberalismo global, ha generado un sinfín de problemáticas sociales, enfocadas a la ausencia de participación de las comunidades afectadas en el desarrollo de la ciudad, y al desplazamiento intraurbano de las mismas, desconociendo, consecuentemente, los derechos que le son propios al ciudadano y olvidando las prerrogativas a favor de las colectividades afectadas, que son el deber ser de la actuación pública y, por ello, deben ser resarcidas por los mismos causantes implementando un plan de migración pleno que dé garantía de las facultades reconocidas al ciudadano en el arquetipo de unEstado Social de Derecho. Enel contexto de esta vulneración masiva de derechos con ropaje de legalidad y fundamentalmente del derecho a la ciudad, la Clínica Jurídica de Interés Público UNAULA, ha adoptado un rol de acompañante socio jurídico mediante la interposición de acciones constitucionales respecto a dos casos esenciales que permiten la comprensión de dicho fenómeno, justificado a partir de las estrategias clínicas ofrecidas para la mitigación de los efectos nocivos producidos por el paulatino crecimiento socioeconómico y urbano. Nuestra intención será la de vislumbrar los componentes que emergen de tal situación.
\end{abstract}

8 Estudiante de sexto semestre de Derecho, Universidad Autónoma Latinoamericana, integrante de la Clínica Jurídica de Interés Público UNAULA desde febrero de 2018. Correo electrónico: Ivisalzate4@gmail.com

9 Estudiante de sexto semestre de Derecho Universidad Autónoma Latinoamericana, integrante de la Clínica Jurídica de Interés Público UNAULA desde febrero de 2018. Correo electrónico: valito-1998@hotmail.com 
Desplazamiento intraurbano en Medellín por proyectos de desarrollo...

Palabras clave: Neoliberalismo, desplazamiento intraurbano, participación, reasentamiento, globalización.

\begin{abstract}
The creation of city models starting from urbanistic interventions chords with standards from global neoliberalism have generated endless social issues focused on the absence of participation of the communities affected by the development of the city, and the intraurban displacement of these. In this problematic the main actor is presented as a conjugation of public and private entities in charge of the design of the city, generating a diffuse panorama regarding the posibility of determination of the main actor, unknowing consequently the rights that are own to the citizen and forgetting the prerogatives in favor of the affected collectivities wich are the must be of the public performance and therefore must be compensated by the same causers implementing a plenary migration plan that guarantees the faculties recognized in the archetype of Rule of Law, paradoxical to this, the State presents itself to the particular as a facilitator of the socioeconomic development. In this context of massive vulneration of rights with clothing of legality, and fundamentally of the right to the city, the Juridic Clinic of Public Interest UNAULA, has adopted a role of companion socio juridic through the interposition of constitutional actions regarding two esential cases that allow the understanding of this phenomenon, justified from the clinical strategies offered for the mitigation of the harmful effects produced by the gradual urban and socioeconomic growth. Our intention will be to glimpse the components that emerge from such situation.
\end{abstract}

Keywords: Neoliberalism, intraurban displacement, participation, resettlement, globalization.

\title{
Introducción
}

Este escrito expone cómo el desplazamiento intraurbano por la ejecución de mega proyectos privados o de interés social, se presenta en los actuales modelos de ciudad formal como consecuencia del expansionismo histórico de los modelos económicos y urbanos neoliberales, que, adaptados a las políiticas globales de desarrollo, conllevan a la configuración de directrices de planeación de ciudad excluyentes de la participación real de las comunidades potencialmente afectadas, contribuyendo así a la creación de nuevos espacios periféricos, informales, y precarios de hábitat humano. En este sentido, las ciudades latinoamericanas resaltan como exponentes 
del impacto negativo producido por los procesos desorganizados de migración que, aunadas a la implementación actual de las políticas neoliberales por medio de la ordenación territorial realizada por los entes administrativos de las mismas, ha conllevado a que diferentes comunidades sean desplazadas de su hábitat de interacción social y cultural, bajo condiciones que desconocen sus prerrogativas como colectividad.

De este escenario, surge el imperativo de análisis del contexto fáctico en el cual se enmarca en la ciudad de Medellín, para lo cual se realizará un recorrido sobre las consecuencias que han derivado de los megaproyectos privados y de interés social, resaltando la necesidad de integración de políticas participativas y democráticas, dando también vigencia al derecho de los habitantes a la ciudad lo que esta tiene para ofrecer a ellos como espacio para el efectivo ejercicio de sus derechos.

En este contexto, el rol participativo adoptado por la Clínica Jurídica de Interés Público UNAULA se encuentra dirigido a la mitigación y pormenorización de los impactos devenidos de este expansionismo, por lo cual, las estrategias han sido claves para la asistencia de las colectividades que se encuentran vulneradas y carentes de amparo administrativo, jurídico y social, creando en la actualidad retos que se encuentran en contravía a las decisiones que la administración considera pertinentes, y en virtud del cual, es indispensable su presencia como constructor socio jurídico del Estado Social de Derecho, mediante la reestructuración y formulación de nuevas estrategias de litigio adaptables al dinamismo de las problemáticas sociales surgidas con el transcurso del tiempo, que, en principio, han sido considerados individualmente y posteriormente como colectividad, pero que a pesar de la consagración de una amplia gama de derechos en la Carta Política a su favor, carecen de garantías de cumplimiento inmediato, requiriendo además de la interposición de reiteradas accionesjudiciales que en razón de circunstancias de forma o de fondo pueden resultar desfavorables para la protección de los derechos, necesitando entonces de una participación activa que materialice una protección efectiva de aquellos que carecen de los medios de conocimiento jurídicos.

\section{Antecedentes históricos del desplazamiento intraurbano}

Para abordar una de las problemáticas más considerables de la actualidad, comoes el proceso migratorio des de el panorama del desplazamiento intraurbano, es 
necesario presentaruna serie de antecedentes que pueden ser considerados los principales causantes de que las personas migren de su lugar de morada, de su origen y cultura. Como ciudadanos pertenecientes a una población determinada por ellugar donde desarrollan sus proyectos de vida y evolucionan en su integridad social, se ven afectados constantemente por la creación de megaproyectos alentados por el afán de la globalización y el neoliberalismo, estos últimos como uno de los principales intérpretes para la producción de dichos fenómenos. Por ende, resulta relevante y procedente sostener el origen, concepto y desempeño que tienen estos modelos adoptados por la mayoría de los países occidentales para lajustificación de su avance e innovación. El Estado colombiano y específicamente la ciudad de Medellín han acogido estos modelos de forma afabley hospitalaria, incluso como un principio fundante de sus políticas y directrices.

Es menester comprender el origen del neoliberalismo como "teoría política y económica que tiende a reducir al mínimo la intervención del Estado" (Real Academia Española). Sus orígenes se remiten principalmente a la década del cuarenta del siglo XX en la cual el filósofo, jurista y economista Von Hayek fundamenta el modelo capitalista con tintes neoliberales en el libro denominado El camino de la SerVIDUMBRE el cual indica los beneficios de tener libertades individuales y económicas, alejando al Estado de la administración de recursos, reconociendo que, para que exista la seguridad económica se requiere de aquellos derechos individuales netamente efectivos que garanticen una economía sostenible y progresiva.

Más adelante, se da una evolución de la concepción del neoliberalismo llevada a cabo por Ludwig Erhard que se desempeñó como canciller federal de Alemania. Sus inicios en la política se dieron principalmente en 1939 cuando se desarrollaba la Segunda Guerra Mundial, su participación no tuvo un éxito contundente debido a que sus ideales liberales económicos iban en contra de la Alemania nazi, por lo que su modelo de economía se tornó eficaz y suficiente para implementarlo y nombrarlo como consejero económico del gobierno militar de Estados Unidos debido a que se encontraba en pleno auge el surgimiento capitalista; posterior a esto, y a finales de la Segunda Guerra Mundial, Erhard logrósu participación en su país Alemania ejecutando sus prototipos económicos, llevando a cabo la ideología neoliberal no determinándose de forma precisa con este término. 
Luego de estas primicias del neoliberalismo y de la decaída que produjo la posguerra en la economía, los principales países capitalistas se encontraron en una profunda necesidad de buscar, con urgencia, la cura al modelo tradicional que los llevaba abatidos y debido a esto se implementaron y se fortalecieron, cada vez más, las ideas neoliberales logrando una gran cabida dentro de los países, determinando la dosis necesaria para la enfermedad que atravesaban. No quedándose muy atrás, Inglaterra con la ayuda de Margaret Thatcher. Allí se empezaron a implementar una serie de políticas que iban en pro de una economía que tenía como objetivo principal la privatización de las empresas e instituciones, así como la educación y reducir al máximo la participación de los sindicatos en aras de garantizar el surgimiento y afianzamiento de una nueva y radical economía liberal.

Avanzando en el panorama del despliegue del neoliberalismo, es propio decir que Latinoamérica no se queda estancado en poner en funcionamiento dicho modelo, y uno de los primeros países en implementarlo fue Chile en 1973, con la llegada de la dictadura de Augusto Pinochet, quien planteaba los cimientos de lo que sería su modelo económico basado en un documento denominado "El Ladrillo", según el cual se refundaría el modelo económico del Estado chileno. Dicho texto realizado por economistas y empresarios originarios de Chile que efectuaron sus estudios y especializaciones en la Universidad de Chicago en Estados Unidos, razón por la que los denominaron como los "Chicago boys" (Molina, 2013), tenía plasmado todo el desarrollo económico que se implantaría. Pinochetlogró instaurar una mentalidad de privatización fuerte. De "El Ladrillo" se deben resaltar algunos extractos que denotan los fundamentos neoliberales que produjo uno de los mayores cambios en Chile: "Sin embargo, el desarrollo económico de este período es lento, y el cambio en las aspiraciones de todos los sectores que genera el desarrollo cultural, social y político no encuentra los medios suficientes para satisfacerlos" (Boys, 1992).

El sistema de mercados implica mecanismos claros, automáticos e impersonales de premios y castigos, a la vez que proporciona incentivos suficientes que se avienen a una característica central del ser humano: su capacidad y voluntad de obtener para sí y su familia un destino mejor (Boys, 1992).

Se puede observar cómo se conjuga lo que se promete en la modernización estatal y económica, y las adversas consecuencias que se pueden obtener. El neoliberalismo fue atractivo en países como Argentina, Bolivia, Brasil, entre otros. Porsu 
parte, Colombia en el artículo 58 de su Constitución Política de 1991, empieza a filtrary garantizar dentro del desarrollo de su economía, la protección de la propiedad privada:

Se garantizan la propiedad privada y los demás derechos adquiridos con arreglo a las leyes civiles, los cuales no pueden ser desconocidos ni vulnerados porleyes posteriores. Cuando de la aplicación de una ley expedida por motivos de utilidad pública o interés social, resultaren en conflicto los derechos de los particulares con la necesidad por ella reconocida, el interés privado deberá ceder al interés público o social. La propiedad es una función social que implica obligaciones. Como tal, le es inherente una función ecológica. El Estado protegerá y promoverá las formas asociativas y solidarias de propiedad. Por motivos de utilidad pública o de interés social definidos por el legislador, podrá haber expropiación mediante sentencia judicial e indemnización previa. Esta se fijará consultando los intereses de la comunidad y del afectado. En los casos que determine ellegislador, dicha expropiación podrá adelantarse por vía administrativa, sujeta a posterior acción contenciosa-administrativa, incluso respecto del precio (Colombia, 1991).

Es esta una de las formas de apertura que brinda el Estado colombiano al neoliberalismo, que más adelante se vislumbrará: la injerencia de los nuevos modelos de economía y globalización perturban de forma tajante a la persona, obligándola a desplazarse de su entorno de ciudad y recurrir a otros lugares.

Pero el neoliberalismo no llega hasta ahí, ya que más adelante surge unfenómeno prometedor de trabajar juntos como hermanos y lograr que todos tengan las mismas condiciones, mismas culturas y mismas formas de crecimiento jurídico, económico y social por lo cual, le damos paso al fenómeno de la globalización.

La globalización propone unos mismos requisitos para todos y cada uno de los países para que éstos usen unos méto dos de desarrollo que les permitan entrar en un crecimiento de carácter general que, en su conjunto, presente las mismas características económicas, urbanísticas y culturales sin que se presente diferenciación alguna entre los países y, antes que nada, ofrecer una igualdad-desigual que si bien, de cara al mercado, es una idea innovadora e incluyente, ante los ojos de la realidad es el impulso para la creación de desplazamiento social y económico de las más grandes potencias a las otras que mercantilmente se denominan como medianas y pequeñas potencias, que al tratar de alcanzar el modelo de globalización y neoliberalismo a 
la par (Globalización Neoliberal) se desentienden en su totalidad de las formas de mercado interno, de las formas arquitectónicas pertenecientes a cada desarrollo por pertenecer a un continente y lugar determinado, y sobretodo olvidan al componente principal de toda sociedad que es el ser humano, que en este escrito y por el entorno a tratar se denominará como ciudadano.

Es evidente que la sumatoria entre neoliberalismo y globalización presenta una cultura de la exclusión que, por los factores que estos modelos llevaninnatos ensu teoría, permiten que el individuo busque la salida a lo que es contrario a su naturaleza o mejor, innatural de donde se desempeñó, por lo cual cada vez que el ciudadano migre, es posible que los sitios a los que vaya, estén permeados de este modelo de desarrollo tan "igual" y generalizado, por lo que de forma inmediata van a ser objeto de huida en búsqueda de lugares que posean características similares a las oriundas, donde la persona no encontrará una satisfacción que le permita funcionar diariamente conforme a sus costumbres y tradiciones. Además, el ciudadano de la actualidad se encuentra en la constante migración de cultura y de ciudad por parte de las políticas que impone específicamente el neoliberalismo global, como lo es el acceso de entes privados extranjeros en el modelo de construcción de la ciudad, agente que ha sido uno de los principales actores en el desplazamiento intraurbano en la búsqueda de lograr la simetría de las grandes potencias con las medianas y mínimas, específicamente en los países latinoamericanos.

\section{Problemática de desarrollo urbano en Latinoamérica}

Dentro del contexto anterior, es importante resaltar la problemática de urbanización poblacional que padecen las ciudades latinoamericanas, bajo el paradigma de un mundo neoliberal, globalizado, y como producto de los procesos migratorios de las zonas rurales impactadas por los aconteceres políticos, económicos y sociales que acompañaron su innatural desarrollo. Los grandes cambios territoriales que tuvieron lugar en las urbes latinoamericanas desembocaron de dicho proceso brusco de migración, que se asocia esencialmente a los movimientos revolucionarios que se produjeron dentro de cada país y se extendieron por todo el siglo XX hasta la actualidad (Gatica, 1975).

Lo anterior, trajo consigo una situación de sobrepoblación urbana por el cual los asentamientos humanos se ubicaron en las zonas limítrofes y periféricas de las 
ciudades, en perjuicio de condiciones de hábitat dignas, existiendo, en la mayoría de casos, contextos de informalidad urbana que imposibilitaban la configuración de un espacio efectivo para el ejercicio pleno de derechos y deberes, desbordando en este sentido las facultades de la institucionalidad, y presentando retos económicos, sociales, políticos, culturales e, inclusive, democráticos para comunidades específicas dentro de las urbes. Esta problemática, exige la imperante necesidad de ser atendida por todos los actores que han intervenido en ella, tanto públicos como privados, que en razón al incremento de las deficiencias cualitativas y cuantitativas de vivienda, transporte, vías, equipamiento, infraestructura, espacio público y prestación de servicios públicos esenciales, que ponen en cuestión el estado de bienestar de las poblaciones (Mazo \& Tamayo, 2014), requieren de la construcción de una ciudad participativa y democrática, en la cual se garantice el equitativo usufructo de los bienes y recursos que ella ofrece.

Medellín, sin ser la excepción a esta situación, ha presentado históricamente un desordenado crecimiento urbano por los procesos de migración desarrollados desde el siglo xIX hasta la actualidad, con especial auge en la mitad del siglo XX, y que en conjunto con las dinámicas económicas y políticas que han confluido en el interior de la ciudad y el paulatino incremento poblacional por los altos índices de asentamientos humanos, han resultado en la materialización de situaciones de hábitat precarias en condiciones de informalidad urbana, que, aunadas a las condiciones geográficas inherentes al suelo urbano de la ciudad, reportan estados de alerta ambiental por encontrarse ubicadas su mayoría en zonas de alto riesgo.

Elinicio del fenómeno migratorio en la ciudad data de aproximadamente el año 1840 con la conformación del barrio "El Salado" por un grupo de esclavos emancipados, pero no sería sino hasta el siglo XX cuando la ciudad se convertiría en un real atractivo económico para las poblaciones rurales y extranjeras, debido principalmente al auge de las actividades comerciales, industriales y neoliberales que se desarrollarían en su interior (Mazo \& Tamayo, 2014), y configuraron la expansión de las laderas, zonas limítrofes y periféricas en las cuales se ubicarían las poblaciones inmigrantes.

Sumado a esto, Medellín en losúltimos años por la gestión de sus autoridades administrativas y de planeación e independiente a éstos, particulares y empresarios, han desarrollado actividades de adopción, promocióne implementación de las políticas globales y neoliberales de construcción de ciudad como los expuestos previa- 
mente, agravando únicamente el problema de hábitat, vivienda y asentamiento urbano ya latente en la ciudad debido a la inexistencia de planes de reasentamiento plenos, previos y concertados que puedan ser implementados durante la ejecución de proyectos urbanos, ya sean estos de interés social y desarrollados por la municipalidad, o megaproyectos de carácter privado, que den garantía efectiva de la preservación de los derechos de las comunidades próximas a ser intervenidas durante el desarrollo de los mismos mediante su reacomodación urbana, y que aminoren los impactos negativos que ellas puedan padecer en razón de su eminente desplazamiento y reubicación. Dichos impactos implicarían transformaciones socioculturales de las colectividades afectadas, materializado por perjuicios relativos al rompimiento de los vínculos que ellas hayan construido respecto a su entorno; a la alteración de sus oportunidades y desarrollos económicos, generando posibles situaciones de subsistencia precaria; al goce de servicios públicos esenciales, cuya afectación derivaría del reasentamiento en zonas de riesgo, periféricas, o de difícil acceso para la prestación de ellos; a su derecho fundamental a una vivienda digna en todos sus ejes, en cumplimiento de la jurisprudencia constitucional de la Corte Constitucional y tratados internacionales sobre la materia; y en lo sumo, representando un deterioro manifiesto de la calidad de vida de los habitantes.

En este sentido, es particularmente importante el papel de la administración, pues le corresponde el deber de vigilancia y salvaguarda de las prerrogativas reconocidas constitucionalmente a las colectividades, y participa activamente en el diseño de ciudad de acuerdo con sus proyectos de interés social, los cuales a simple vista aparentan operaciones administrativas dirigidas a la materialización de un interés superior, cuyo propósito consiste en la satisfacción de una necesidad actualmente insatisfecha de un sector de la población, pero que tras un examen minucioso del mismo se evidencian las falencias estructurales que conllevan a los costos sociales de un desarrollo urbano irresponsable.

La construcción de proyectos de interés social implica sacrificios y deberes para las personas que se ven obligadas a trasladar sus viviendas para dar paso al progreso delaregión, y cómo han argumentado sus promotores, se debe a la complejidad de la operación que se debe adelantar, pues ella exige una cuantificación de los individuos a ser intervenidos y una cualificación de los impactos negativos que se producirá a aquellos, sin olvidar también, la necesaria consideración del espacio y la población 
urbana que será posteriormente receptora de dichas colectividades (Botero, 2006). Aun así, los retos técnicos que se presentan en materia de reasentamiento urbano durante el desarrollo e implementación de obras de interés social, corresponde a la administración ejecutar las actividades, operaciones, y tareas de forma diligente y responsable, en cumplimiento de los objetivos y principios previstos por la normatividad colombiana y los tratados internacionales sobre desarrollo territorial y urbano, dando siempre prevalencia a las condiciones de hábitat dignas, tanto presentes como futuras, de las comunidades objeto de intervención.

De esta forma, se hace menester la integración de políticas democráticas y participativas que permitan la materialización de los principios de equidad, justicia social, y den garantía de la participación activa de la población impactada por la realización de obras de interés social mediante la construcción mutua entre ellas, promotores públicos y privados, de un plan de reasentamiento pleno y previo y así, alcanzar un modelo de ciudad equitativo, participativo y ordenado, que facilite el aprovechamiento igualitario de los bienes que la ciudad pueda reportar a los ciudadanos. Para ello, dicha problemática debe ser abordada a profundidad desde dos momentos esenciales: el primero, compuesto por la conceptualización y exposición del derecho a la ciudad y la participación ciudadana, siendo ellos esenciales para la adopción de políticas urbanas y públicas que reporten soluciones efectivas y definitivas para estas poblaciones; el segundo, por la presentación y análisis de dos casos concretos, en los cuales la Clínica Jurídica de Interés Público UNAULA adoptó un rol de acompañante socio jurídico mediante la interposición de acciones constitucionales, y que otorgan una mayor comprensión fáctica.

\section{La participación ciudadana en la ejecución de megaproyectos privados $y$ de interés social}

Las dinámicas contemporáneas de desarrollo urbano, adscritas a las políticas neoliberales de construcción de ciudad, conllevan naturalmente a contextos de reasentamiento involuntario de poblaciones debido a las transformaciones territoriales de las cuales es objeto su lugar de asentamiento. Lo anterior, aplicado en el contexto de un Estado Social de Derecho, implica la obligación inexorable de las autoridades territoriales de velar por la materialización de los intereses supremos previstos en la 
Constitución Política, garantizando un espacio de legitimidad administrativa encaminada a la satisfacción de derechos fundamentales y colectivos de las comunidades que serán reasentadas, buscando atenuar las cargas excesivas que estas puedan soportar, y constituyendo condiciones dignas de hábitat que correspondan a espacios plenos para el ejercicio de sus facultades y la realización de sus proyectos individuales.

Estosprocesos dereasentamiento exigen de condiciones especialespara la creación efectiva de un contexto de hábitat propicio, pues su desarrollo, para ser pleno, exige la consideración y aplicación de los principios de participación, concertacióny orientación del proceso, pero además, requieren de una visión interdisciplinaria que integre todas las áreas que deben ser tenidas en cuenta para la concreción de escenarios de hábitat plenos (Botero, 2006). Lo anterior no es en vano, pues la jurisprudencia constitucional y la normatividad internacional, en conjunto con los lineamientos internacionales sobre desarrollo urbano y territorial, contemplan la participación ciudadanay democrática como derecho y deber político, por el cual el ciudadano asume de forma autónoma las oportunidades que puedan crear para sí o para otros en el giro ordinario de sus actividades.

En este sentido, la Carta Democrática, en su artículo 6, reconoce la participación de la ciudadanía en las decisiones relativas a su propio desarrollo y, la Convención Americana sobre Derechos Humanos, en su artículo 23, reconoce el derecho político por el cual todos los ciudadanos se encuentran facultados a participar en los asuntos deinterés público. En nuestra Carta Política, la participación ciudadana se encuentra prevista como principio en su preámbulo, al asegurar un marco democrático y participativo en miras a garantizar un orden político, económico y social justo, y como derecho fundamental en el artículo 40, al facultar a los ciudadanos a participar en las diferentes formas de participación democrática previstas por la misma o por la ley.

La participación ciudadana es por tanto, principio fundante del Estado Social de Derecho, pues considera al ciudadano como elemento esencial e indispensable para la estructura del mismo, y lo faculta, para hacer parte de las actividades públicas, fundamentado desde la óptica del ejercicio democrático en la composición política de la sociedad. No obstante, la Corte Constitucional ha planteado que el derecho fundamental a la participación ciudadana no se agota en las instancias electorales y políticas, pues este abarca inclusive aquellos contextos decisorios que puedan tener 
repercusiones en la vida de la ciudadanía (C-351 , 2013). Por ello, la participación ciudadana se compone íntegramente de dos visiones: la primera de ellas, eminentemente política, y ejercida por medio de los agentes participativos como representantes cívicos; y por otra, de intervención directa de la ciudadanía, mediante los diversos mecanismos democráticos y participativos. Por lo cual, no es extraño que la Ley 388 de 1997 en su artículo 4, enfatice de forma reiterativa, el derecho fundamental a la participación ciudadana, y que, además, los POThagan referencia a ellos en su composición estructural, como sucede con el del año 2005 de Medellín al señalarcomo propósito del mismo la construcción de una ciudad participativa.

Lo anterior, exige entonces de las administraciones territoriales como promotoras de aquellos proyectos de interés social, que al ser ejecutados potencialmente podrían desencadenar procesos de reasentamiento y reubicación poblacional, que se dé la participación efectiva, real y oportuna de las colectividades afectadas por las obras, de forma tal, que se dé garantía de la conservación de las condiciones cualitativas y cuantitativas de vida digna de dichas comunidades. Lo anterior, en concordancia con la protección del entorno del individuo, comprendido desde lo social, familiar, y personal, hasta aquellas construcciones culturales con sus conciudadanos, en virtud de la preservación de los vínculos consuetudinarios de ellos con relación a su lugar de asentamiento. Pero la participación ciudadana en la ejecución de proyectos de interés social no puede ser meramente informativa, las administraciones no pueden apelar exclusivamente a la promoción de actividades de divulgación, en perjuicio de la calidad de vida de los habitantes, que son excluyentes del querer y de la voluntad de las comunidades por tratarse de planes de reasentamiento que no atienden a sus necesidades materiales, mediatas e inmediatas.

La planeación de ciudad debe de ser óptima, ordenada, equitativa, y esencialmente participativa, por medio de acciones democráticas reales y efectivas, no meramente informativas, que presenten puentes comunicativos entre las pretensiones de la institucionalidad, manifestados mediante el ejercicio de competencias administrativas, y de las comunidades objeto de reasentamiento, por medio de medidas concretas y sustanciales que permitan el ejercicio de su derecho a la participación ciudadana. Dichos puentes deben de culminar en la creación de planes de reasentamientos plenos, previos y concertados, que integren las necesidades mediatas e inmediatas de las comunidades con las potestades administrativas de los entes e 
statales, y dando siempre prevalencia al bienestar de la calidad de vida y dinámicas propias de los grupos a reasentar.

Por lo anterior, se debe ir más allá de los modelos de urbanización y planeación territorial impuestos por los modelos neoliberales, pues los costos sociales por la consecución, creación y materialización de la ciudad modelo presentada por la globalización son irreparables. En este sentido, la creación de planes de reasentamiento plenos, previos y concertados en atención a las condiciones socioculturales de sus receptores, y de sus necesidades mediatas e inmediatas, se reporta como una solución a la planeación desordenada y torpe de las urbes, y constituye el deber ser de la administración partiendo de los lineamientos internacionales, políticos y constitucionales sobre participación ciudadana. En la planificación de la urbe deben participar todos aquellos potencialmente afectados, de forma tal, que se les reporten correlativamente nuevas oportunidades y medidas que faciliten su desplazamiento territorial, y compensen los impactos negativos, daños y perjuicios que puedan padecer por el mismo.

\section{Reconocimiento e integración del derecho a la ciudad en las políticas de reasentamiento urbano}

Entonces, producto de todos los fenómenos y modelos que han sido desarrollados en este escrito, fue necesario acudir a una figura jurídica que apenas tiene sus comienzos en el año 1967 definida por HenriLefebvre como el derecho de los habitantes urbanos a construir, decidir y crear la ciudad, y hacer de esta un espacio anticipado de la lucha anticapitalista (Camargo, 2016).

Este derecho se presenta como un derecho colectivo, que se debe desarrollar jurídicamente de tres formas. Primero como un equitativo usufructo de lo que la ciudad tiene para brindar a sus habitantes; segundo como el mandato de construcción colectivay participativa de asuntos de ciudad; y tercero, como el goce efectivo de los derechos humanos en contextos urbanos. Por lo que se hace necesaria una relación entre lo que el ciudadano tiene como derecho y deber, y lo que tiene la ciudad para ofrecer a este como perteneciente a un desarrollo urbano local que le brinde unas políticas públicas para garantizar y hacer efectivo ese derecho, puesto que como lo ha expresado Lefebvre, el ciudadano debe dejar de distinguirse por su nombre, familia, y 
en cambio debe definirse por la forma en que el sujeto pertenece a una red de prácticas sociales determinadas conforme a su hábitat, ciudad y región (Camargo, 2016).

Este derecho es visible en la Carta mundial por el derecho a la ciudad en 2005, este derecho es un derecho que por su naturaleza internacional que consagran los derechos humanos y fundamentales dentro de los derechos civiles y políticos, de los cuales son titulares todas las personas de forma individual, son exigibles por todos los ciudadanos de forma colectiva y de responsabilidad de todos los gobernantes y administradores. Esta Carta señala en su primer artículo que: "el derecho a la ciudad seestablece como el derecho colectivo de todosloshabitantes dela ciudad, en particular de los grupos vulnerables o marginados, que los legitima para lograr el completo ejercicio de la libre determinación y un adelantado nivel de vida". Por lo tanto los titulares del derecho son to dos los ciudadanos que pretendan y quieran beneficiarse de todo aquelusufructo que la ciudad tenga para ellos, pero es necesario resaltarque este derecho es de especial protección para las poblaciones que se encuentren en un estado de vulneración, desventaja o desavenencia, es por esto necesario que estas poblaciones deben contar con una igualdad respecto de los demás lugares de ciudad, y distribución de recursos y servicios para la población y ciudadanía.

\section{Retos clínicos}

\subsection{Retos en la ejecución del plan parcial de renovación urbana del sector de} Naranjal - Medellín

En el primer semestre del año 2015, el señor Federico Aguilar presentó a la Clínica Jurídica de Interés Público UNAULA una carta mediante la cual, solicitaba a esta, acompañamiento socio jurídico debido a la situación de afectación que padecían los habitantes del barrio Naranjal de Medellín por la ejecución del Plan Parcial de Renovación Urbana del Sector.

Dicha problemática nació con la expedición del Decreto 1284 de 2000, por el cual se formula y adopta el Plan Parcial, que no fue objeto de revisión y ajustes sino hasta el año 2009 con la expedición del Decreto 1309, y con la particularidad de haber sido elaborado sin la participación del Concejo de Medellín y de las autoridades ambientales.

Posterior, a la Empresa de Desarrollo Urbano se le encomienda el rol de operador social del proyecto, encargada de realizar los censos poblacionales exigidos porla ley 
para dar inicio al proceso de enajenación voluntario y reasentamiento poblacional. No obstante, la comunidad prontamente se percató de la comisión de actos irregulares por parte de la administración y el operador social, como por ejemplo, la exclusión en su realización de determinados pobladores, y en perjuicio de propietarios, moradores, poseedores, y tenedores que habitaban la zona. En este sentido, resaltó también la falta de participación real de la comunidad en las actividades de implementación, situación que se evidenciaba en su omisión al realizar modificaciones unilaterales al plan en lo relativo a la ubicación in situ de las VIS y VIP.

Con fundamento en los hechos anteriores fue interpuesta una acción popular que tenía por objeto la protección de los derechos colectivos de los habitantes del barrio el Naranjal. A partir de ello, la Clínica Jurídica de Interés Público UNAULA interviene en el proceso, mediante el desarrollo y presentación de un amicus curiae, el cual, contó con una estructura dividida en tres partes: La primera, que expuso el objetivo del amicus curiae en un proceso, y su incidencia en el caso concreto; segundo, abordando los argumentos de apoyo sobre el derecho colectivo a la realización de construcciones, edificaciones y desarrollos urbanos respetando las disposiciones jurídicas, de manera ordenada, y dando prevalencia a la calidad de vida de los habitantes, y como en el caso concreto, la modificación unilateral de las disposiciones previstas en el Decreto 1309 de 2009 representaban una potencial vulneración del derecho colectivo en mención.

\subsection{Retos en la ejecución del metrocable El Picacho}

Otro de los retos importantes y actuales que han enriquecido la experiencia de la Clínica Jurídica de Interés Público UNAULA, es la ampliación de las líneas de transporte Sistema Integrado Metro de Medellín en convenio con el municipio de Medellín titulado "Metrocable El Picacho" que, como procedimiento de expansión de transportey urbanización, ha creado una serie de inconvenientes que justificándose en el interés social y la utilidad pública, han dejado en el olvido el derecho de los ciudadanos y un grupo de personas en específico, pertenecientes a los Barrios La Paralela y Doce de Octubre. La problemática radica en que los espacios habitados por los integrantes de La Paralela y el Doce de Octubre se necesitan para la realización de la línea del Metro de Medellín, acto seguido, el reasentamiento y el avalúo de las viviendas no cuentan con una planificación y estructuración juiciosa sobre el futuro de las personas que 
van a ser desalojadas. Además, solicitan que éstos se despojen de sus lugares de vivienda, desconociendo su rumbo siguiente de la implementación de este megaproyecto generando en ellos una zozobra, debido a que a estos individuos se les pretende deshabitardesushogaressintener un reasentamiento previo, pleno y concertado que dé cuentas de que van a quedarnuevamenteen una vivienda sin que las alteraciones o modificaciones que se presenten sean inferiores a las condiciones de vida como se encontraban inicialmente.

Producto de esta puesta en peligro de los derechos fundamentales y constitucionales de estos ciudadanos y conforme a la Ley 472 de 1998 se logró instaurar por parte de la CJIP de la Universidad Autónoma Latinoamericana, una acción popular contra el Metro de Medellín, municipio de Medellín y el Instituto Social de Vivienda y Hábitat de Medellín (ISVIMED) por violar flagrantemente los literales b y m del artículo 4 de la Ley 472 de 1998, en la cual se pretende declarar la responsabilidad por parte de estos actores debido a que si bien, no garantizan un acceso a una vivienda digna y estas personas están siendo desplazadas, tampoco cuentan con un plan de reasentamiento que sea garante de los intereses constitucionales, patrimoniales y culturales de estas personas, burlándose de la capacidad y goce que éstos tienen de sus derechos por ser pertenecientes a la ciudad, y pormenorizando sus lugares de techo al realizar un avalúo por menos del valor correspondido con el interés y el afán de avanzar en sus obras, ya que se justifica como un crecimiento masivo en transporte y economía que aporta a la ciudad de Medellín, para no desligar su categoría de la más innovadora conforme a las demás ciudades y como se ha venido dando en los últimos tiempos. Otras de las pretensiones se basan en la correcta implementación de un nuevo plan de reasentamiento que cuente con unos fines patrocinadores del debido proceso y la correcta aplicación donde se implemente la participación ciudadana. Además, es inevitable la presentación de vulneración o puesta en peligro del derecho colectivo de la realización de construcciones, edificaciones y desarrollo urbano respetando las disposiciones jurídicas, porque a pesar de que exista una motivación o fin urbanístico e innovador por parte de la administración, éstos deben reconocer que existen unas disposiciones legales que son susceptibles de ser respetadas, debido a que si bien se viene hablando de una serie de políticas exigibles para entrar en el modelo de la globalización, por fortuna y aún las disposiciones legales no cuentan con ese carácter global de tener las mismas normas y reglamentaciones jurídicas para la urbanización 
y edificación. Por ende, aquellos están llamados a asegurar el beneficio y la calidad de vida a los que están por intervenirse o se van a intervenir.

A estos ciudadanos no se les ha garantizado un reasentamiento pleno, previo y concertado que dé cuentas de un resarcimiento producto de las expansiones urbanas; hoy por hoy estas personas tienen la calidad de desplazados por obras urbanas y megaproyectos. Se ha puesto el máximo empeño en lograr que se afiancen unos derechos que les son inherentes a la persona, con acciones judiciales que coetáneamente siguen en marcha luego de haber sido admitida la acción popular.

\section{Conclusiones}

- Lanegligencia administrativa, respecto a la obligación de implementarpolíticas públicas participativas, ha generado como consecuencia, la migración poblacional de las comunidades impactadas, debido a que se ven obligadas a soportar injustamente la carga de avanzar no conforme al desarrollo cultural y social de su entorno, si no a los lineamientos neoliberales de urbanización; Lo anterior, ha conllevado al diseño de una ciudad excluyente, desigual y periférica, obstaculizando el desarrollo de las facultades individuales de las comunidades y el de sus proyectos de vida, configurándose un espacio inequitativo para el ejercicio de los derechos de los ciudadanos afectados por el desarrollo de la ciudad en beneficio del supuesto "interés general", y en el caso de Medellín, haciéndola merecedora del distintivo de "La Ciudad más Innovadora", obviando claramente, las condiciones de debilidad manifiesta en las cuales la Administración municipal abandona a las comunidades por ese interés general.

- El gran reto migratorio para la Clínica Jurídica UNAULA ha consistido en el desarrollo de un litigio estratégico que tenga por objeto el reconocimiento de las prerrogativas participativas y democráticas de las comunidades en el desarrollo de las políticas urbanas y en la construcción de ciudad. Teniendo como principal problemática la inexistencia de la positivización de las consecuencias derivadas de la migración, de las garantías colectivas que cada vezse encuentran disminuidas por la adaptación de modelos estatales que impiden el amparo del individuo como factor principal social, siendo reemplazado este por la economía como sector central de protección. 


\section{Referencias}

Botero, J. D. (2006). El Reasentamiento Poblacional: Fenomeno Social, Político y de Progreso. Estudios Socio-Juridicos, Bogotá, 157-160.

Boys, C. (1992). "El Ladrillo", Base de la Política Económica del Gobierno Militar Chileno. Santiago de Chile: Centro de Estudios Públicos Monseñor SóteroSanz.

C-351 , C-351 DE 2013 (Corte Constitucional 19 de junio de 2013).

Camargo, F.M. (2016). El Derecho a la ciudad: de Henri Lefebvre a los análisis sobre la ciudad capitalista contemporánea.

Colombia. (1991). Constitución Política de Colombia.

Gatica, F. (Diciembre de 1975). Cepal (Comisión Económica Para América Latina Y EI Caribe). Obtenido de Comisión Económica Para América Latina y el Caribe, Repositorio Digital: https://repositorio.cepal.org/handle/11362/12563

Martínez, H., Gómez, V., Vásquez, S., Rendón, O., Pulgarín, E., \& González, B. (2017). Amicus Curiae de la Clínica Jurídica de Interés Público UNAULA. Indisciplinas, 117-136.

Mazo, S., \& Tamayo, G. (2014). Potencialidades de la participación en la construcción de ciudad desde intervenciones urbanas en asentamientos precarios. America Latina Hoy, 120-134.

Molina, P.(2013). ¿Qué queda del modelo económico de Augusto Pinochet? BBC.Com, 1. Real Academia Española. (S.F.). España. 